\title{
Chapter 8 \\ Building Resilience to Drought in the Sahel \\ by Early Risk Identification and Advices
}

\author{
Patrizio Vignaroli
}

\begin{abstract}
Agriculture in the Sahel region is characterized by traditional techniques and is strongly dependent on climatic conditions and rainfall. As a consequence of recurrent droughts in East and West Africa, integrated famine Early Warning Systems (EWS) have been established in order to produce and disseminate coherent and integrated information for prevention and management of food crises. Since the early 1990s, analysis tools and simulation models based on satellite meteorological data have been developed to support Multidisciplinary Working Groups (MWG) in cropping season monitoring. However, many of these tools are now obsolete from the IT perspective or ineffective due to unavailability of regularly updated meteorological data. To ensure a long-term sustainability of operational systems for drought risk zones identification CNR-IBIMET has developed 4Crop, a coherent Open Source web-based Spatial Data Infrastructure to treat all input and output data in an interoperable, platform-independent and uniform way. The 4Crop system has been conceived as a multipurpose tool in order to provide different categories of stakeholder, from farmers to policy makers, with effective and useful information for climate risk reduction and drought resilience improvement. Advice to farmers is a fundamental component of prevention that can allow a better adaptation of traditional cropping systems to climatic variability. Past experiences show that agro-meteorological information and weather forecasts can play a key role for food security, reducing the vulnerability of farmers, strengthening rural production systems and increasing crop yields. A participatory and cross-disciplinary approach is essential to build farmers' trust and to develop effective integration between scientific and local knowledge to increase the rate of dissemination and utilization of advice.
\end{abstract}

Keywords Drought $\cdot$ Early warning systems $\cdot$ Risk management $\cdot$ Adaptation

P. Vignaroli $(\square)$

National Research Council-Institute of Biometeorology (IBIMET),

Via Giovanni Caproni 8, 50154 Florence, Italy

e-mail: p.vignaroli@ibimet.cnr.it

(C) The Author(s) 2017

M. Tiepolo et al. (eds.), Renewing Local Planning to Face Climate

Change in the Tropics, Green Energy and Technology,

DOI 10.1007/978-3-319-59096-7_8 


\subsection{Introduction}

Agriculture in the Sahel region is characterized by traditional techniques and is strongly dependent on climatic conditions and rainfall. Moreover, the vulnerability of rainfed crop production systems to drought is worsened by soil degradation, low resilience levels due to poverty and inability to implement effective risk mitigation strategies (FAO 2011).

Food security of the rural population largely depends on environmental conditions and on spatial and temporal climate variability (Jouve 1991). In general, low rainfall during the growing season can lead to lower crop yields and, sometimes, to food crises (Sultan et al. 2005).

Crop yields may suffer significantly with either a late onset or early end of the rainy season, as well as a high frequency of damaging dry spells (Mugalavai et al. 2008). Early rains at the beginning of the season are often followed by dry spells that can last a week or longer. As the amount of water stored in the soil at this time of year is negligible, crops planted early can suffer water shortage stresses during a prolonged dry spell (Marteau et al. 2011). The choice of sowing date is therefore of paramount importance to farmers. Indeed, a successful early planting can produce an earlier crop that may have a higher yield (Sivakumar 1988). Later planting reduces the risk of early crop failures, but yields can decline because of the shorter growing period remaining before the end of the rains (Jones 1976).

Concerning dry spells, there are two extremely critical periods when water shortage can cause wilting of the plants and yield reductions. The first occurs immediately after sowing when plants are germinating. A dry spell at this time can halt germination and cause a sowing failure, requiring a second sowing with consequent loss of seeds and growing days. The second critical period occurs during flowering when a water deficit can severely reduce crop yields (Benoit 1977). The ability to effectively estimate the onset of the season and potentially dangerous dry spells thus becomes vital for planning crop practices aiming to minimize risks and maximize yields. Increasing yearly variability due to climate change has made farmers' traditional knowledge on the planning of sowing and selection of crop type and variety rather ineffective (Waha et al. 2013).

This paper describes the activities of CNR-IBIMET to set up a web-based and open access crop monitoring system for drought risk reduction and resilience improvement.

\subsection{The Area of Interest}

The geographical area coincides with the western part of the Sahel region. The area extends between Senegal and Chad and is bounded to the north and south by the Saharan and Sudanese climatic zones (Fig. 8.1). 


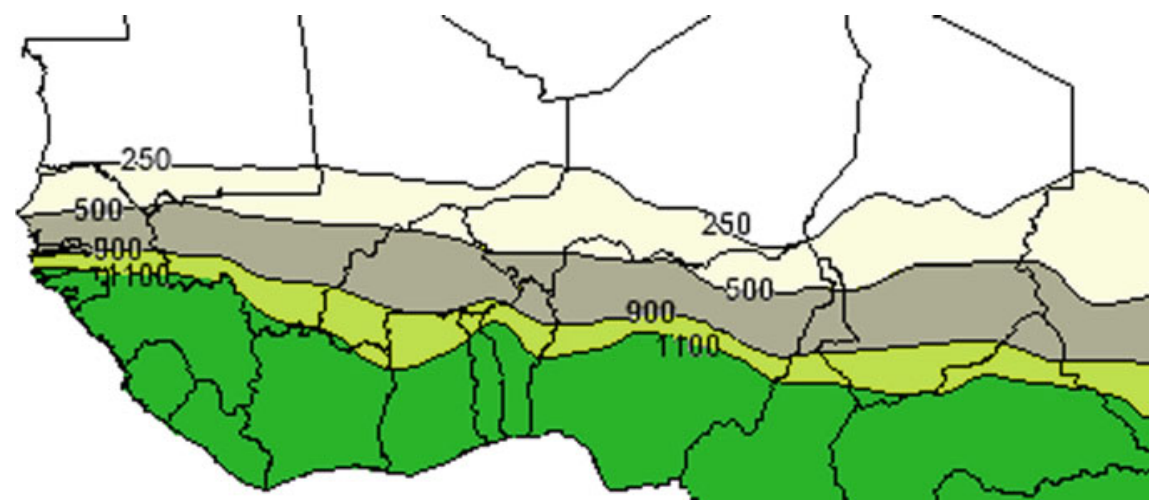

Fig. 8.1 Climatic zones in Western Sahel based on mean annual rainfall 1961-1990: Sahelian (250 $500 \mathrm{~mm}$ ), Soudanese-Sahelian $(500-900 \mathrm{~mm})$, Soudanese $(900-1,100 \mathrm{~mm})$, Guinean $>1,100 \mathrm{~mm}$ (SDRN-FAO)

The wet period mostly occurs in the summer, following the African monsoon. The onset of the rainy season essentially depends on latitude but also has high inter-annual variability (Sivakumar 1988). The rainfall pattern has a unimodal distribution and the annual cumulated rainfall shows a gradient from north to south, going from 150 to $600 \mathrm{~mm}$ (Wickens 1997).

With some exceptions, the Sahel landscape is composed of semi-desert grassland, scrub and wooded grasslands, where Acacia species (Acacia spp.) play a dominant role (Nicolini et al. 2010). Although the area has been inhabited for at least 9000 years, in the last few decades, over-exploitation of land, closely related to population growth, has led to soil depletion and lower productivity (Di Vecchia et al. 2006).

Human pressure and climate change are leading to a rapid and often irreversible degradation of natural resources (Wezel and Rath 2002).

Millet and sorghum are the primary food crops. In the northern part of the region, which is very sensitive to climatic fluctuations, the most widespread crop is millet, with a cycle length of between 70 and 90 days, depending on the variety. Its water requirement varies from 300 to $500 \mathrm{~mm}$ (Bacci et al. 1992). Even if the drought resistance of this crop is naturally high, its sensitivity to water stress greatly increases in the period just after sowing: an interruption of rainfall following the onset of the rainy season can cause the death of seedlings (Kleschenko et al. 2004). Crop failure leads to loss of seeds as well as greater labor demands as farmers must replant their fields. Delayed sowing also entails risks of missing the nitrogen that becomes available through mineralization following the first rains, which is especially important when no fertilizer is applied. (Bacci et al. 1999).

In the southern Sahel areas, the better climate conditions allow farmers to implement different strategies of intensification and diversification of cropping systems. Cereals are often associated with cash crops, such as groundnut and sesame, although these crops are more vulnerable to drought. 


\subsection{Evolution of Early Warning Systems for Food Security in the Sahel}

In the late 1970s, as a consequence of recurrent droughts that occurred in East and West Africa (Nicholson 2001), famine struck millions of people, creating a need for national authorities and the international community to coordinate efforts to limit the dramatic impact on the affected population. Since then, an integrated famine early warning system (EWS) has been established in West Africa by the Permanent Inter-State Committee for Drought Control in the Sahel (CILSS), which is still one of the most effective and reliable mechanisms operating in sub-Saharan Africa in order to prevent and manage food crises (Genesio et al. 2011).

The CILSS EWS is based on three complementary components:

- an information network operating at country level and involving national technical services and international organizations in order to produce and disseminate coherent and integrated information on population's food security status;

- a regional-national coordination, led by CILSS, to facilitate dialogue, consultation and coordination between partners;

- a relief body, to manage emergency activities at national level.

In the early 2000s, the EWS activities were still mainly focused on food availability by monitoring agricultural seasons and agro-climatic events. The main information product concerned the national cereal balance, often coupled with a qualitative assessment of food risk zones provided by agro-meteorological models or composite indicators (Tefft et al. 2006).

However, this approach has proven to be outdated and ineffective in identifying complex multi-source crises such as that of Niger in 2005 (Cornia and Deotti 2008; Vallebona et al. 2008).

A conceptual model to integrate multi-disciplinary data and for the harmonization of information flow within the existing EWS has been provided by the Food Crises Forecasting Timetable (CPCA), developed by AGRHYMET regional Centre of Niamey, Niger, in collaboration with the World Meteorological Organization. The CPCA was designed to respond to decision makers' need to be alerted at an appropriate time depending on the extent of the food crisis (local, national or regional), the coping capacity of the affected population and amount of required food aid (Vignaroli et al. 2009).

This approach was then transferred and implemented in an operational way in the Harmonized Framework (Cadre Harmonisé) for the analysis and identification of areas at risk and vulnerable groups in the Sahel established by CILSS in collaboration with national and international organizations involved in the Food Crisis Prevention Network in the Sahel (RPCA). The Cadre Harmonisé is a process aiming to achieve technical consensus and to enhance information generated by existing information systems in order to evaluate food and nutrition insecurity on an objective and consensual basis (CILSS 2014). Since 2013, Economic Community 
of West African States (ECOWAS) has selected the Cadre Harmonisé as the main reference framework for food security analysis in 16 countries of West Africa and provides tools for the classification, analysis and reporting of food insecurity, as well as joint approaches for undertaking monitoring, assessments, data collection, and database management.

The Multidisciplinary Working Groups (MWGs) led by National Meteorological Services (NMSs) play a strategic role in the operation of national EWSs especially during the rainy season. MWGs are in charge of providing timely and reliable information on rainfed crops status and agro-hydro-meteorological conditions in support of decision-making processes, from farmers to national and international stakeholders.

\subsection{An Open Source Geoprocessing Tool for Drought Monitoring}

Early warning systems operate on two levels: prevision and prevention. Prevision is mainly based on tools and models utilizing numeric forecasts and satellite data to predict and monitor the growing season. This approach is centered on the early identification of risks and the production of information within the time prescribed for decision-making (Vignaroli et al. 2009). Agrometeorological models have a central role in this chain, as they can transform meteorological data into levels of risk for agriculture (Di Vecchia et al. 2002), identifying the geographical areas exposed to food insecurity risk due to cereal production shortage in relation to local demand. Advice to farmers is thus a fundamental component of prevention, allowing a proactive response through a better adaptation of the traditional crop calendar to climatic variability (Di Vecchia et al. 2006; Roudier et al. 2014).

Since the early 1990s, crop monitoring analysis tools and simulation models based on meteorological satellite data have been developed within different international cooperation programs to allow monitoring of the cropping season in CILSS countries (Samba 1998; Traore et al. 2011). Software was usually a stand-alone application, transferred to NMSs but without continuous user support or updates. Furthermore, the scarcity of funds for hardware and software maintenance, besides the unavailability of regularly updated and timely meteorological data, led to the failure or ineffectiveness of many of these tools.

In order to meet the needs of the CILSS meteorological services and to ensure a long-term sustainability of operational systems for drought risk zones identification CNR-IBIMET has developed 4Crop (Vignaroli et al. 2016), a coherent Open Source web-based Spatial Data Infrastructure to treat all input and output data in an interoperable, platform-independent and uniform way (Fig. 8.2). This activity is supported by the Global Facility for Disaster Reduction and Recovery (GFDRR) The Challenge Fund. 


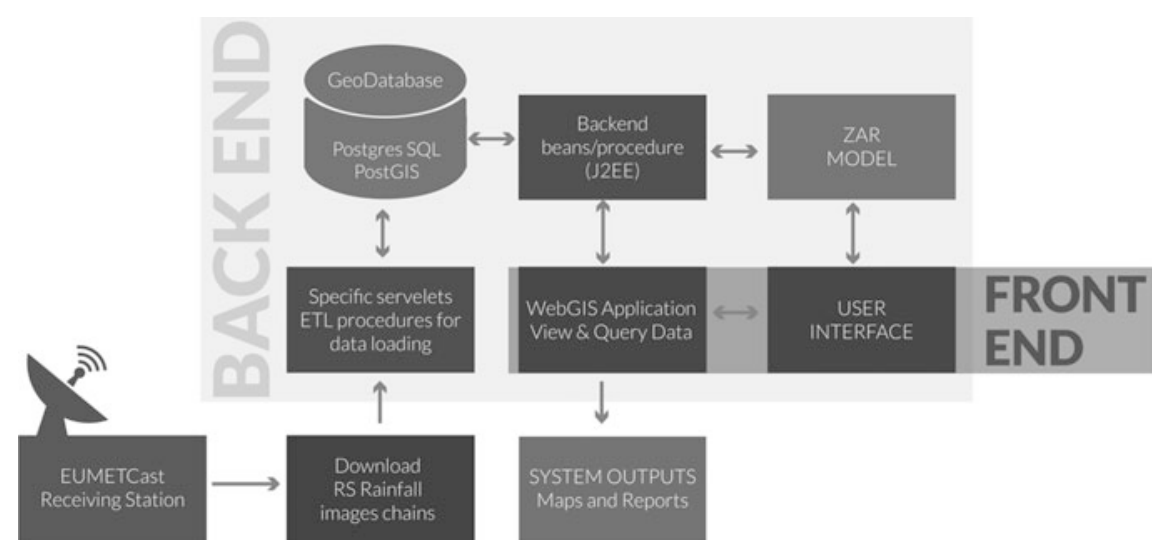

Fig. 8.2 System architecture (Vignaroli et al. 2016)

This web application, targeting Niger and Mali National Meteorological Services, is based on the Crop Risk Zone (CRZ) model (Vignaroli et al. 2016), the updated version of Zone à Risque (ZAR) model (CNR-IBIMET 2006) distributed as stand-alone software to the NMSs of CILSS countries within the framework of SVS (Vulnerability Monitoring in the Sahel) Projects, implemented with the World Meteorological Organization at the AGRHYMET Regional Center of Niamey, ${ }^{1}$ Niger. The ZAR model accuracy was validated with field data collected in 2006 and 2007 in Mali, Niger and Senegal within the framework of the AMMA project ${ }^{2}$ with the support of National Meteorological Services (Bacci et al. 2009). An operational test was also performed on the 2009 season in Burkina Faso, Chad, Mauritania, Mali, Niger and Senegal in collaboration with the NMSs (Bacci et al. 2010).

The CRZ model performs a soil water balance to evaluate the satisfaction of crop water requirements in each phenological stage during the growing period. The model is initialized by a rain threshold $(10,15$ or $20 \mathrm{~mm})$; this threshold depends on the crop calendar and the varieties traditionally used by farmers in different agro-ecological zones (Bacci et al. 2009). To best adapt simulation to the real behavior of various cropping systems, the CRZ model allows users to customize some parameters: type of crop and variety, sowing conditions (rain threshold and start of simulation period) and extent of analysis area. So far the model has been tested on the following four crops: pearl millet (85 and 130 days), cowpea (75 days), groundnut (100 and 140 days), sorghum (110 days).

\footnotetext{
${ }^{1}$ AGRHYMET (Agriculture, Hydrology, Meteorology Regional Center) is a specialized agency of the Permanent inter-state committee against drought in the Sahel (CILSS).

${ }^{2}$ African Monsoon Multidisciplinary Analyses (AMMA) is an international project to improve knowledge and understanding of the West African monsoon (WAM) and its variability.
} 
The model data input can be summarized as follows:

- Gridded daily cumulated rainfall estimate images.

- Gridded daily cumulated precipitation forecast (0-240 h).

- Gridded average daily PET from MOD16 Global Terrestrial Evapotranspiration data set.

- Average start of growing season (computed on the last 10 years).

- Average end of growing season (computed on the last 10 years).

- Gridded soil water storage capacity from Harmonized World Soil Database (FAO/IIASA/ISRIC/ISS-CAS/JRC 2009).

- Phenological phase lengths and crop coefficient Kc (Allen et al. 1998) for each simulated crop.

Due to the lack of a dense weather station network in Africa and the availability and consistency of long-term rainfall data for the Sahel Region, open satellite-derived data sets have been used to provide the CRZ model with the input data required for analysis. NCEP/NOAA Global Forecast System (GFS) is the reference data source for forecast images at $0.25^{\circ}$ resolution; the Climate Prediction Center (CPC) Rainfall Estimator supplies daily Rainfall Estimates (RFE) at $0.1^{\circ}$ resolution and EUMETSAT Earth Observation Portal makes available historical series of Multi-Sensor Precipitation Estimate (MPE) at $3 \mathrm{~km}$ resolution.

Chains for automatic data downloading have been implemented to ensure a regular update of each data set, while specific procedures and services have been built up to handle model input data flow.

The CRZ model is composed of three modules of analysis (Fig. 8.3). The first two use rainfall estimate images as input data and operate in diagnostic mode. The third module employs precipitation forecast images and works in predictive mode.

\section{Installation Module}

It provides an overview of the dates of successful seeding, showing areas where sowing failures may have occurred due to water stress. Zones where a crop was installed later than normal - because of the late onset of the rain season or due to a first sowing failure - are also highlighted. The following outputs are generated:

- image of crop installation dates (where sowing and crop installation conditions occurred);

- image of sowing failure dates (where sowing conditions occurred but not installation conditions);

- image of re-sowing dates (where, after a sowing failure, sowing conditions occurred again);

- image of crop installation anomalies (comparison between actual and average crop installation dates).

\section{Monitoring Module}

It performs a diagnostic of crop condition after its installation. The algorithm assesses the satisfaction of water requirements and shows the areas where a water stress happened. The model also provides an estimate of the potential crop yield as 


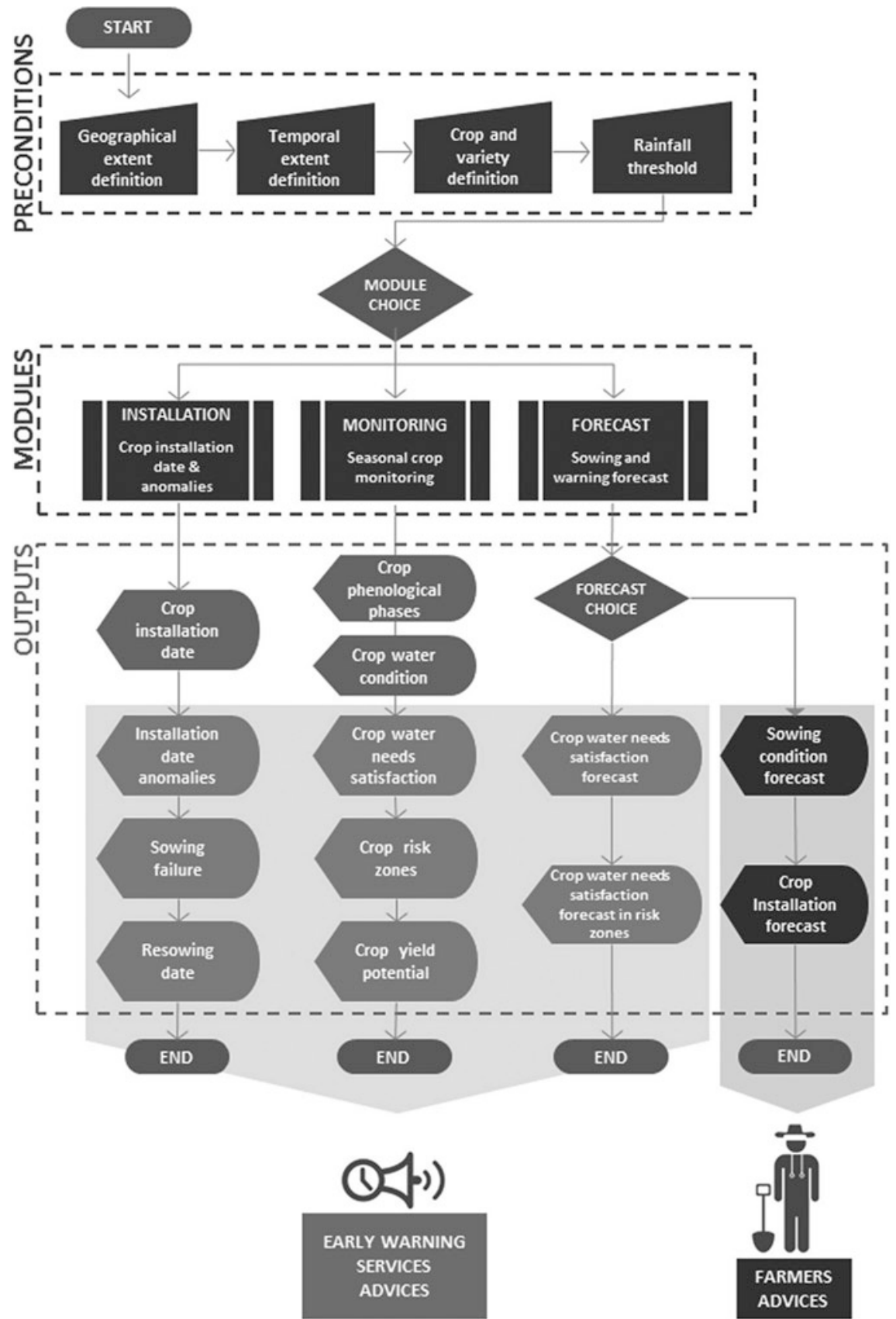

Fig. 8.3 CRZ model flow chart 
a consequence of the intensity of water stress and the phenological stage in which it occurred. This module produces the following outputs:

- image of actual phenological phases image (where crop installation occurred);

- crop water requirements satisfaction (water stress level in areas where crop installation occurred);

- available soil water (water actually available in the soil for areas where crop installation occurred).

\section{Forecast module}

It is composed of two sub-routines. The first, Sowing Forecast, provides the following outputs on the occurrence of favorable conditions for sowing and the subsequent crop installation:

- forecast date of sowing conditions (where forecasted rainfall satisfies sowing conditions);

- forecast date of crop installation (where the last ten-days estimated rainfall satisfied sowing conditions and the forecasted rainfall allows crop installation conditions to be satisfied).

The second, called Warning Forecast, performs a prognosis on the possible occurrence of a water stress situation for crops already sown. This module produces the following outputs:

- forecast of crop water requirements satisfaction (in areas where crop installation occurred, forecasted satisfaction level of crop water requirements is shown);

- forecast of crop water requirements satisfaction in risk zones (in areas where crop stress conditions have already been identified, crop water requirements are forecasted).

Graphic Users' Interfaces (GUI) and specific WEB GIS applications have been implemented to allow users initializing of analysis modules and to perform model outputs management and visualization.

\subsection{Results and Discussion}

The challenge of the 4Crop web application is to provide open access to CRZ model output and results. The goal is to support CILSS early warning system and any other local users in decision-making to foster climatic risk management and resilience to drought. In order to avoid a language barrier that could prevent a wider use of the web application, 4Crop is available in French, the official language of the target countries ${ }^{3}$ (Fig. 8.4).

\footnotetext{
${ }^{3}$ In the first phase of GFDRR project, activities have been focused on Mali and Niger. The second phase will concern Burkina Faso, Mauritania and Senegal.
} 


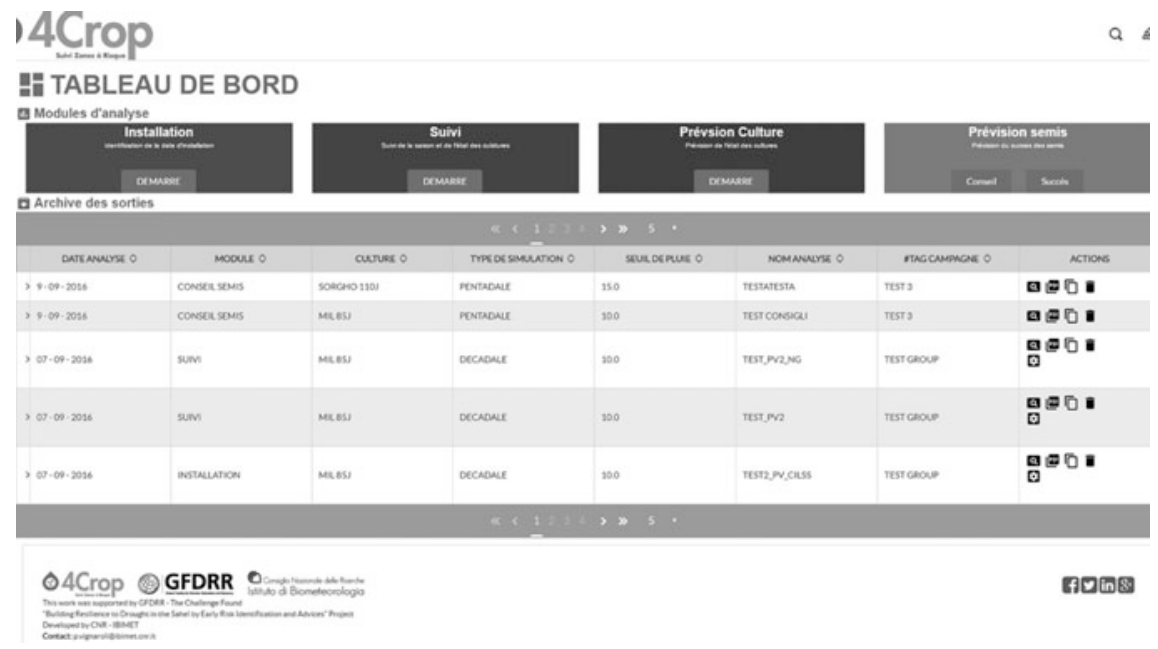

Fig. 8.4 System users' interface

Although Internet connections in most African countries may be a limitation because of poor efficiency of communications networks, the decision to adopt a web-based system allows problems due to the continuous need for software updating and maintenance to be overcome and it also ensures a timely and regular update of input satellite data. In addition, a stand-alone version would still need a large amount of data to be downloaded via the Internet to update the database of satellite images, while the loading of system user interface, if well designed and implemented, requires significantly less resources. Finally, Internet services are reaching good quality in the capital cities of most Sahel countries (Nyirenda-Jere and Biru 2015) where the system users (NMSs) are located.

Moreover, the proposed approach is meant to encourage the integration and sharing of interoperable and open source solutions, thus contributing to the setting up of distributed climate services in developing countries (WMO 2014).

The involvement of national Meteorological Services, as primary users of the system, during all the phases of its development allowed 4Crop to be made easier and more intuitive to use by improving the ergonomics of the Graphic Users' Interface through a co-design approach. This has also contributed to better tailoring the system outputs in terms of both content and formats, to best meet the needs of different users.

In this sense, 4Crop system has been conceived as a multipurpose tool (Fig. 8.5) in order to provide different categories of stakeholders, from farmers to political decision makers, with effective and useful information for implementing specific actions at national and local level for climate risk reduction and drought resilience improvement.

The outputs provided by the 4Crop system in diagnostic mode are specifically addressed to support drought monitoring activities performed by the national 


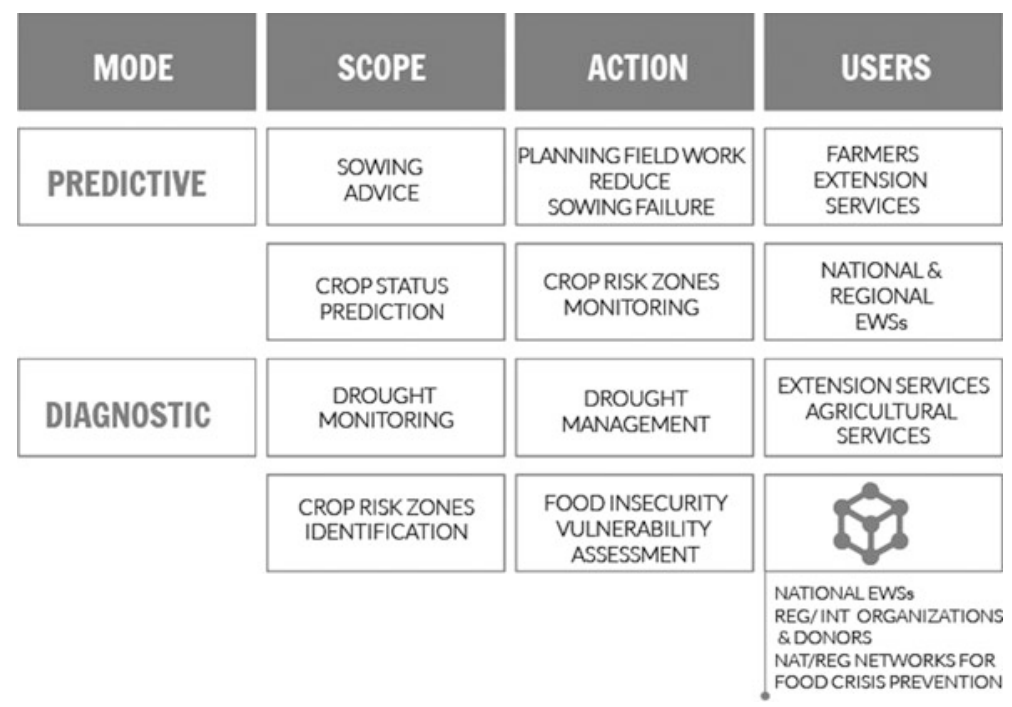

Fig. 8.5 "4Crop" multipurpose tool

Multidisciplinary Working Groups during the agro-pastoral season. An early identification of crop risk areas represents a key step in providing a preliminary evaluation on the dimension of expected food crises (local, national, regional) in order to alert national and international institutions responsible for their prevention and management (Vignaroli et al. 2009). Moreover, monitoring of crop risk areas throughout the cropping season contributes to the final assessment of the real food insecurity status of the population concerned within the framework of national and regional EWS set up in West Africa (CILSS 2014).

The 4Crop products generated in predictive mode, based on GFS 10-days precipitation forecast, are mainly conceived for "advisory-support" activities to farmers, in order to implement appropriate, short-term strategies for minimizing drought risk in crops (i.e. identification of the optimal sowing period, adoption of suitable cropping practices to improve soil fertility and water use efficiency) and contribute to building farmers' resilience.

Field observations in Mali since 1983 show that when farmers use agrometeorological information to plan the sowing date and choose the varieties to be used, yields are higher than with traditional choices (Hellmuth et al. 2007). In addition, some simulation studies performed in Cameroon indicate that crop yields of maize and groundnut with an optimal planting date are usually higher than yields obtained using traditional ones under climate change (Laux et al. 2010; Tingem et al. 2009). This is in agreement with Waha et al. (2013), as the adaptation of sowing dates in this latter study usually resulted in higher crop productivity in most regions and cropping systems of sub-Saharan Africa.

Advice to farmers is indeed a fundamental component of prevention that allows a better adaptation of the traditional crop calendar to climatic variability. 
Past experiences show that agro-meteorological information can play a key role for food security, reducing the vulnerability of farmers, strengthening rural production systems and increasing crop yields (Kleschenko et al. 2004,; Pérarnaud et al. 2004). For example, from 1983 to 2004, the«Projet Pilote d'Assistance Agro-météorologique aux Paysans» (AAMP 2005) in Mali proved an increase of about 30\% in cereal production. In Senegal, starting from 1992 to 1994, the «Projet d'Assistance Météorologique à l'Agriculture au Sénégal»(AMAS) estimated a 20\% increase in cereal yields by using agrometeorological advice. The METAGRI program, promoted by the World Meteorological Organization and operating since 2008 in several West African and Sub-Saharan countries currently represents a reference framework for the development and implementation of agro-meteorological services for farmers. In 2016, a new stage of METAGRI is being launched, named METAGRI SERVICES, with the aim of reinforcing and extending the operational model of agrometeorological assistance to rural areas, which includes the development of decision-making support systems based on reliable remote sensing products and tested crop models (WMO 2016). This new approach is supported by the availability of seasonal and 10-day rainfall forecasts (Njau 2010) and the possibility for farmers to access IC technologies (mobile phones) in order to disseminate information in rural areas (Aker and Fafchamps 2015).

Empirical studies among African farmers have shown that climate forecasts can help reduce their vulnerability to drought and climate extremes, while also allowing them to maximize opportunities when favorable rainfall conditions are predicted (Roudier et al. 2014; Martinez et al. 2012). However, it should be underlined that weather forecasts in situations of climate uncertainty generally don't modify the farmer's decision, but reinforces what has already been decided based on his/her own experience and observations (Roncoli et al. 2009). In fact, farmers combine information from different sources and multiple timeframes (Orlove et al. 2010). So they have some expectation about the coming season based on prior experience, empirical observations, and local knowledge, and then adjust their strategies when shorter-term forecasts and real-time information become available (Orlove et al. 2010).

In this regard, the analysis of the behavior of different groups of smallholder farmers in two agro-ecological areas of Senegal provides examples of how farmers could use predictive climate information at different timescales, as seasonal and 10-day rainfall forecasts. (Roudier et al. 2014). In most cases, farmers identify at least one strategy they could use in response to forecasts. Most adaptation strategies pertain to 10-day rather than seasonal forecasts, though the latter are used especially where farmers have a wider range of options in planning preparatory activities, as well as the choice of crops and/or varieties to sow, the amount of mineral or organic fertilizer to distribute before sowing, extent of the crop surfaces.

Adjusting sowing date is the most common change in traditional practices adopted by farmers in response to 10-day rainfall forecasts; farmers decide to sow earlier or later than originally planned depending both on the configuration of rainfall in the forecasted 10 days (wet or dry) and in the preceding 10 days. 
This information is particularly important at this time, which is marked by high uncertainty and anxiety for farmers (Roudier et al. 2014). On the same bases, farmers could also decide to intensify weeding practices - to control weed proliferation and facilitate infiltration to limit runoff and soil erosion-as well as to anticipate harvest to prevent germination of grains or avoid damage by pests and diseases that thrive in humid conditions (Roudier et al. 2014).

Overall, although farmers put their trust in local knowledge, they are open to receiving and integrating scientific knowledge in their decisional process. This encourages extending the use of rainfall forecasts in producing and disseminating advice as a fundamental part of climate services to farmers in order to foster a proactive reaction to climate change and to cope with drought. In this sense, the adoption of a participatory, cross-disciplinary approach is essential to build farmers' trust and develop a fruitful collaboration between scientific and traditional knowledge. Indeed, this interaction has been recognized as fundamental for the adoption of innovation in climate change adaptation because the enhancement of local knowledge facilitates effective communication and increases the rate of dissemination and use of advice (Nyong et al. 2007).

\subsection{Conclusions}

4Crop is a multipurpose system implemented in collaboration with the National Meteorological Services of Niger and Mali to monitor the cropping season and provide an early identification of crop risk zones in order to establish effective responses for drought risk management at different levels. Within the perspective of the setting-up of distributed climate services, the overall 4Crop approach could represent an enabling factor to allow a switch from generic information to advice tailored to specific user needs. Indeed, 4Crop outputs have been designed as elements of information chains targeted on two main user categories under the principle of information-action.

The first group are decision makers at national/regional level who use information to implement actions and policies to prevent and manage food crises and strengthen food security of the population. In this case, the critical elements are represented by the sustainability of early warning systems and the ability to generate timely and appropriate information for decision makers. Strengthening of the capacity of national institutions - particularly weather services - as well as the setting up of distributed climate services that allow stakeholders at different levels to access and share information products through web services protocols and standards, can thus represent elements that facilitate decision-making and improve its effectiveness.

The second group of users are decision makers at local level, essentially farmers, who have to decide which crops and how to grow them. This requires not only finding a suitable solution for translating information products into services that are simple but effective for farmers, but also establishing a framework for 
communication and collaboration between scientific institutions, national technical services and rural communities for an effective dissemination and adoption of the advice.

To be effective and sustainable, climate services for farmers must be integrated into a concerted and participatory strategy (including content and format of advice, communication channel, partnership with other local stakeholders and training), which enables final users to adopt scientific innovation in ways that are socially acceptable and environmentally sound.

In terms of beneficiaries, the approach will also pay special attention to gender: in many cases, women are the backbone of the farming community, however they are at a disadvantage in their access to climate and weather information as well as access to training programs.

\section{References}

AAMP. 2005. Assistance Météorologique Opérationnelle au Monde Rural au Mali. Développement-Acquis-Perspectives. Coopération Suisse.

Aker, J.C., and M. Fafchamps. 2015. Mobile phone coverage and producer markets: evidence from West Africa. The World Bank Economic Review 29 (2): 262-292. Doi:doi.org/10.1093/wber/ lhu006.

Allen, R.G., L.S. Pereira, D. Raes, and M. Smith. 1998. Crop evapotranspiration-Guidelines for computing crop water requirements - FAO irrigation and drainage paper 56. Rome: FAO.

Bacci, L., G. Maracchi, and B. Senni. 1992. Les stratégies agrométéorologiques pour les pays Sahéliens. Florence: IATA-CeSIA.

Bacci, L., C. Cantini, F. Pierini, G. Maracchi, and F.N. Reyniers. 1999. Effects of sowing date and nitrogen fertilization on growth, development and yield of a short day cultivar of millet (Pennisetum glaucum L.) in Mali. European Journal of Agronomy 10 (1): 9-21. doi:10.1016/ S1161-0301(98)00046-X.

Bacci, M., V. Tarchiani, P. Vignaroli, L. Genesio, and A. Di Vecchia. 2009a. Identification et suivi des zones à risque agro-météorologique au Sahel. Rome: Aracne Editrice.

Bacci, M., A. Di Vecchia, L. Genesio, I. Hassan, M. Ndiaye, V. Tarchiani, and P. Vignaroli. 2009. D 5.2.e: AMMA information products tested within the CPCA for EW at national and farmer's scale. African Monsoon Multidisciplinary Analysis (AMMA) project.

Bacci, M., A. Di Vecchia, L. Genesio, V. Tarchiani, and P. Vignaroli. 2010. Drought impact detection on crops in the Sahel: a case study for the 2009 campaign. In proceeding of the GI4DM 2010 Conference Geomatics for crisis management, Feb 2-4, Turin, Italy.

Benoit, P. 1977. The start of the growing season in Northern Nigeria. Agricultural Meteorology 18: 91-99.

CILSS-Comité Permanent Inter-Etats de Lutte contre la Sécheresse dans le Sahel. 2014. Identification et analyse des zones à risque et des populations en insécurité alimentaire et

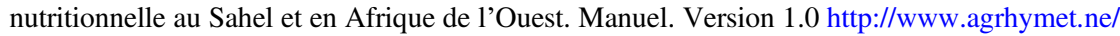
PDF/Manuel\%20CH_version\%20finale.pdf. Accessed 8 July 2016.

CNR-IBIMET. 2006. SPM Suivi des pluies par Meteosat \& ZAR Modèle Zone à Risque. Version 2.0. Centre Regional AGRHYMET. ISBN 88-900502-1-7.

Cornia, G.A., and L. Deotti. 2008. Niger's 2005 food crisis: extent, causes and nutritional impact. EUDN/WP, 15. https://www.researchgate.net/profile/Giovanni_Cornia/publication/ 237773711_NIGER'S'_2005_FOOD_CRISIS_EXTENT_CAUSES_AND_NUTRITIONAL_ IMPACT/links/54aab7920cf2bce6aa1d58f5.pdf. Accessed 5 July 2016. 
Di Vecchia, A., P. Vignaroli, and B. Djaby. 2002. Les crises alimentaires et les systèmes de prévision au Sahel. https://www.researchgate.net/publication/267374263_Les_crises_ alimentaires_et_les_systemes_de_prevision_au_Sahel. Accessed 12 July 2016.

Di Vecchia, A., M. Bacci, G. Pini, V. Tarchiani, and P. Vignaroli. 2006. Meteorological forecasts and agrometeorological models integration: a new approach concerning early warning for food security in the Sahel. In AARSE 2006: Proceeding of the 6th AARSE international conference on earth observation and geoinformation sciences in support of Africa's development, 30 Oct2 Nov 2006, Cairo, Egypt: The National Authority for Remote Sensing and Space Science (NARSS). ISBN 1-920-01710-0.

FAO/IIASA/ISRIC/ISS-CAS/JRC. 2009. Harmonized world soil database (version 1.1). FAO, Rome, Italy and IIASA, Laxenburg, Austria. http://www.fao.org/docrep/018/aq361e/aq361e. pdf. Accessed 13 July 2016.

FAO. 2011. The state of the world's land and water resources for food and agriculture (SOLAW) -Managing systems at risk. Rome-London: Food and Agriculture Organization of the United Nations and Earthscan.

Genesio, L., M. Bacci, C. Baron, B. Diarra, A. Di Vecchia, A. Alhassane, I. Hassane, M. Ndiaye, N. Philippon, V. Tarchiani, and S. Traoré. 2011. Early warning systems for food security in West Africa: evolution, achievements and challenges. Atmospheric Science Letters 12 (1): 142-148. doi:10.1002/asl.332.

Hellmuth, M.E., A. Moorhead, M.C. Thomson, and J. Williams. 2007. Climate risk management in Africa: learning from practice 01-261. Columbia University, International Research Institute for Climate and Society.

Jones, M.J. 1976. Planting time studies on maize at Samaru, Nigeria, 1970-1973. Samaru Miscellaneous Paper (Nigeria) no. 57.

Jouve, P. 1991. Sécheresse au Sahel et stratégies paysannes. Science et changements planétaires/Sécheresse 2 (1): 61-69.

Kleschenko, A., L. Grom, M. Ndiaye, and R. Stefanski. 2004. The impact of agrometeorological applications for sustainable management of farming, forestry and livestock systems. Report CagM WMO/TD No. 1175. World Meteorological Organization.

Laux, P., G. Jäckel, R.M. Tingem, and H. Kunstmann. 2010. Impact of climate change on agricultural productivity under rainfed conditions in Cameroon-A method to improve attainable crop yields by planting date adaptations. Agricultural and Forest Meteorology 150 (9): 1258 1271. doi:j.agrformet.2010.05.008.

Marteau, R., B. Sultan, V. Moron, A. Alhassane, C. Baron, and S.B. Traoré. 2011. The onset of the rainy season and farmers' sowing strategy for pearl millet cultivation in Southwest Niger. Agricultural and Forest Meteorology 151 (10): 1356-1369. doi:10.1016/j.agrformet.2011.05. 018.

Martinez, R., D. Hemming, L. Malone, N. Bermudez, G. Cockfield, A. Diongue, J. Hansen, A. Hildebrand, K. Ingram, G. Jakeman, M. Kadi, G.R. McGregor, S. Mushtaq, P. Rao, R. Pulwarty, O. Ndiaye, G. Srinivasan, E. Seck, N. White, and R. Zougmore. 2012. Improving climate risk management at local level-Techniques, case studies, good practices and guidelines for World Meteorological Organization members. In Risk management-Current issues and challenges, ed. N. Banaitiene. Europe: InTech. doi:10.5772/51554.

Mugalavai, E.M., E.C. Kipkorir, D. Raes, and M.S. Rao. 2008. Analysis of rainfall onset, cessation and length of growing season for western Kenya. Agricultural and Forest Meteorology 148 (6-7): 1123-1135. doi:j.agrformet.2008.02.013.

Njau, L.N. 2010. Seasonal-to-interannual climate variability in the context of development and delivery of science-based climate prediction and information services worldwide for the benefit of Society. Procedia Environmental Sciences 1: 411-420. doi:10.1016/j.proenv.2010.09.029.

Nicholson, S.E. 2001. Climatic and environmental change in Africa during the last two centuries. Climate Research 17: 123-144. doi:10.3354/cr017123.

Nicolini, G., V. Tarchiani, M. Saurer, and P. Cherubini. 2010. Wood-growth zones in Acacia seyal Delile in the Keita Valley, Niger: Is there any climatic signal? Journal of Arid Environments 74: 355-359. doi:10.1016/j.jaridenv.2009.08.017. 
Nyirenda-Jere, T., and T. Biru. 2015. Internet development and internet governance in Africa. ISOC Report. http://www.internetsociety.org/sites/default/files/Internet\%20development\%20 and\%20Internet\%20governance\%20in\%20Africa.pdf. Accessed 22 July 2016.

Nyong, A., F. Adesina, and B.O. Elasha. 2007. The value of indigenous knowledge in climate change mitigation and adaptation strategies in the African Sahel. Mitigation and Adaptation Strategies for Global Change 12 (5): 787-797. doi:10.1007/s11027-007-9099-0.

Orlove, B., C. Roncoli, M. Kabugo, and A. Majugu. 2010. Indigenous climate knowledge in southern Uganda: the multiple components of a dynamic regional system. Climatic Change 100 (2): 243-265. doi:10.1007/s10584-009-9586-2.

Pérarnaud, V., A. Bootsma, P. Isabirye, and B.L. Lee. 2004. Communication of agrometeorological information. Report CagM WMO/TD No. 1254. Geneva: World Meteorological Organisation.

Roncoli, C., C. Jost, P. Kirshen, M. Sanon, K.T. Ingram, M. Woodin, L. Somé, F. Ouatara, B. J. Sanfo, C. Sia, and P. Yaka. 2009. From accessing to assessing forecasts: an end-to-end study of participatory climate forecast dissemination in Burkina Faso (West Africa). Climatic Change 92 (3-4): 433-460. doi:10.1007/s10584-008-9445-6.

Roudier, P., B. Muller, P. D’Aquino, C. Roncoli, M.A. Soumaré, L. Batté, and B. Sultan. 2014. The role of climate forecasts in smallholder agriculture: lessons from participatory research in two communities in Senegal. Climate Risk Management 2: 42-55. doi:10.1016/j.crm.2014.02. 001.

Samba, A. 1998. Les logiciels DHC de diagnostic hydrique des cultures. Prévision des rendements du mil en zones soudano-sahéliennes de l'Afrique de l'Ouest. Sécheresse 9 (4): 281-288.

Sivakumar, M.V.K. 1988. Predicting rainy season potential from the onset of rains in Southern Sahelian and Sudanian climatic zones of West Africa. Agricultural and Forest Meteorology 42: 295-305.

Sultan, B., C. Baron, M. Dingkuhn, B. Sarr, and S. Janicot. 2005. La variabilité climatique en Afrique de l'Ouest aux échelles saisonnière et intra-saisonnière. II: applications à la sensibilité des rendements agricoles au Sahel. Sécheresse 16 (1): 23-33.

Tefft, J., M. McGuire and N. Maunder. 2006. Planning on the future. An assessment of food security early warning systems in sub-Saharan Africa. Synthesis Report. Rome: FAO.

Tingem, M., M. Rivington, and G, Bellocchi. 2009. Adaptation assessment for crop production in response to climate change in Cameroon. Agronomy for Sustainable Development 29 (2): 247-256. doi:10.1051/agro:2008053.

Traoré, S.B., A. Alhassane, B. Muller, M. Kouressy, L. Somé, B. Sultan, P. Oettli, A.C. Siéné Laopé, S. Sangaré, M. Vaksmann, M. Diop, M. Dingkhun, and C. Baron. 2011. Caracterizing and modelling the diversity of cropping situations under climatic constraints in West Africa. Atmospheric Science Letters 12 (1): 89-95. doi:10.1002/asl.295.

Vallebona, C., L. Genesio, A. Crisci, M. Pasqui, A. Di Vecchia, and G. Maracchi. 2008. Large scale climatic patterns forcing desert locust upsurges in West Africa. Climate Research 37: 35-41. ISSN: 1616-1572. doi:10.3354/cr00744.

Vignaroli, P., R. Rocchi, T. De Filippis, V. Tarchiani, M. Bacci, P. Toscano, M. Pasqui, and E. Rapisardi. 2016. The crop risk zones monitoring system for resilience to drought in the Sahel. In Geophysical Research Abstracts 18, EGU2016-16616-3, 2016. EGU General Assembly 2016.

Vignaroli, P., V. Tarchiani, M. Bacci, and A. Di Vecchia. 2009. La prévention des crises alimentaires au Sahel. In Changements globaux et développement durable en Afrique. Rome: Aracne Editrice.

Waha, K., C. Müller, A. Bondeau, J.P. Dietrich, P. Kurukulasuriya, J. Heinke, and H. LotzeCampen. 2013. Adaptation to climate change through the choice of cropping system and sowing date in sub-Saharan Africa. Global Environmental Change 23 (1): 130-143. doi:10. 1016/j.gloenvcha.2012.11.001.

Wezel, A., and T. Rath. 2002. Resource conservation strategies in agro-ecosystems of semi-arid West Africa. Journal of Arid Environments 51 (3): 383-400. doi:10.1006/jare.2001.0968. 
Wickens, G.E. 1997. Has the Sahel a future? Journal of Arid Environments 37 (4): 649-663. doi:10.1006/jare.1997.0303.

WMO-World Meteorological Organization. 2014. Implementation Plan of the Global Framework for Climate Services. WMO, GFCS http://www.wmo.int/gfcs/sites/default/files/implementationplan//GFCS-IMPLEMENTATION-PLAN-FINAL-14211_en.pdf. Accessed 20 July 2016.

Open Access This chapter is licensed under the terms of the Creative Commons Attribution 4.0 International License (http://creativecommons.org/licenses/by/4.0/), which permits use, sharing, adaptation, distribution and reproduction in any medium or format, as long as you give appropriate credit to the original author(s) and the source, provide a link to the Creative Commons license and indicate if changes were made.

The images or other third party material in this chapter are included in the chapter's Creative Commons license, unless indicated otherwise in a credit line to the material. If material is not included in the chapter's Creative Commons license and your intended use is not permitted by statutory regulation or exceeds the permitted use, you will need to obtain permission directly from the copyright holder.

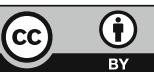

